\title{
Description of Fecal Culture Results in Diarrhea Patients Due To Antibiotic Use
}

\section{Suci Tresna, IGAA Putri Sri Rejeki, Puspa Wardhani}

Department of Clinical Pathology, Faculty of Medicine, Airlangga University/Dr. Soetomo Hospital, Surabaya, Indonesia. E-mail: sctresna@gmail.com

\begin{abstract}
Diarrhea infection is common in developing countries and causes death of around 3 million people every year. Diarrhea is also the second leading cause of death in infants. Riskesdas in 2013 showed 30,775 cases of diarrhea. Causes were such as bacterial infections Salmonella, Shigella, Vibrio, Entamoeba, and Yersinia. Other influences can occur due to viral and fungal infections. Diarrhea is a nosocomial infection that is common in hospitalized patients due to the long-term use of antibiotics caused by Clostridium difficile. This study was a follow-up study of diarrhea patients who received antibiotic therapy for more than two days with the results of $C$.difficile negative toxin, then continued with fecal culture examination. This study aimed to look at the description causes of diarrhea other than C.difficile in patients who received long-term antibiotic therapy. This research is an observational study. Samples were taken from 30 diarrhea patients with $2 \times 24$ hours of antibiotic use who were hospitalized in the ICU, Dr. Soetomo Hospital Surabaya from August 2017 to May 2018. Samples with negative C.difficiletoxin results were then followed by fecal culture examination using conventional methods. The results of culture examination from 30 samples showed three samples with positive culture results extended-spectrum $\beta$ lactamase producing E.coli, two samples positive culture just E.coli, and 25 other samples showed negative culture results. The results of the fecal culture examination showed a description of causes of diarrhea in patients who received antibiotic therapy was pathogenic E.coli (ESBL). The possibility of other causes that cannot be detected from the culture such as viral and fungal infections, still requires further research.
\end{abstract}

Keywords: Fecal culture, bacterial infections, extended-spectrum $\beta$ lactamase

\section{INTRODUCTION}

Diarrhea is a common problem that occurs throughout the world. Diarrhea in the UK and America is lower than in developing countries like Indonesia. Recently, diarrhea can cause the death of 3 million people every year. The incidence is still high and in most regions in Indonesia. Household Health Survey data of Indonesia states that diarrhea is the second cause of death in infants and third in infants and fifth for all ages. ${ }^{1}$ The results of the Riskesdas showed that there were 30,775 diarrhea cases. ${ }^{2}$

A research in 2013 about the morbidity survey conducted by the Diarrhea Sub-Department. Ministry of Health from 2012-2015 results showed increased incidence. Diarrhea morbidity rates among 900 toddlers per 1,000 toddlers in 2012, diarrhea accidents in children under five were $6.7 \%$ (provincial range $3.3 \%-10.2 \%$ ) in 2013 . There were 18 outbreaks of diarrhea in 1,213 patients and 30 death cases with a Case Fatality Rate (CFR) $=2.47 \%$ in $2015 .{ }^{3}$

Diarrhea can be caused by infection or non-infection. The most common agents that can cause diarrhea were as follows: infection bacterial and parasite, viruses, bacteria, and fungi. Non-infectious diarrhea happened due to food poisoning, allergies, lactose intolerance, and stress. Several types of bacterial infection agents that can lead to diarrhea were: Salmonella, Shigella, Vibrio, Campylobacter, and Yersinia. There is a rarely detected, named Clostridium difficile which can cause diarrhea in nosocomial infections microorganism due to long-term antibiotic treatment in hospitals. ${ }^{4}$

First-line treatment for diarrhea is rehydration by electrolyte infusion. It aims to replace lost body fluids due to dehydration. Antibiotics are needed in diarrhea because infections cause $10-20 \%$ of cases. The use of antibiotics must be based on medical considerations to achieve the best therapeutic effect for patients. The use of irrational antibiotics can cause sensitive bacteria to become resistant. ${ }^{1}$ The intensity of antibiotic exposure strongly influences bacterial resistance to antibiotics. The development of bacterial resistance to antibiotics needs to be monitored so that the treatment of diarrhea 
antibiotics can be done in the right selection. ${ }^{4,5}$

C.difficile is a common causative bacterium in nosocomial infections of patients with long-term antibiotic therapy. The data is still limited due to the difficulties in conducting culture. This research is a follow-up study that took samples from diarrhea patients. The inclusion criteria were as follows: received antibiotics for at least $2 \times 24$ hours, and had a negative result in C. difficile toxin. This study aimed to examine the causes of diarrhea, in patients treated in hospitals and received long-term antibiotic therapy.

\section{METHODS}

This research was a follow-up study from previous studies that took samples from adult patients with diarrhea after being given antibiotics at least two days, who were treated in the Inpatient Room of the Internal Medicine and ICU of the Dr. Soetomo Hospital Surabaya. The samples were 30 samples, and C.difficile toxin was examined and showed negative results, then followed by the examination of fecal culture with conventional methods to determine the cause of diarrhea other than C.difficile. Sampling was done from August 2017 to May 2018. The study protocol was approved by the Ethical Commission of Health Research of Dr. Soetomo Hospital with number No.584/
Panke.KKE/IX/2017.

\section{RESULTS AND DISCUSSION}

The sample in this research were 30 samples, consisting of 20 female patients and 10 male patients. The demographic data and clinical characteristics of patients can be seen in Table 1 .

The percentage of gender of patients in this study consisted of 10 males and 20 females, all of whom were adult patients admitted to the Inpatient Ward and ICU of the Dr. Soetomo Hospital Surabaya. The percentage of the patient's gender in this study can be seen in Figure 1.

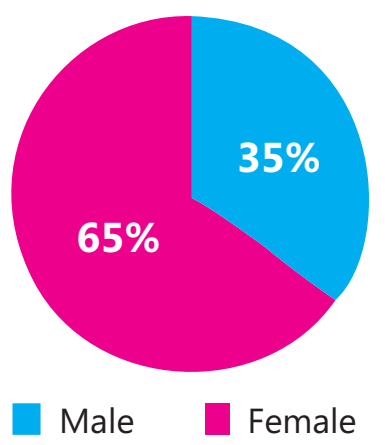

Figure 1. Percentage of gender

Table 1. Demographic data and clinical characteristics of patients $(n=30)$

\begin{tabular}{lc}
\hline \multicolumn{1}{c}{ Variable } & Value \\
\hline Age (year), mean \pm SD & $21-86( \pm 48.94)$ \\
Gender, $\mathbf{n}(\%)$ & $10(33)$ \\
$\quad$ Males & $20(67)$ \\
$\quad$ Females & $2(7)$ \\
Diagnosis, $\mathbf{n}(\%)$ & $5(16)$ \\
$\quad$ Chronic kidney disease & \\
$\quad$ Diabetes mellitus & $5(16)$ \\
Observation of fever & $3(10)$ \\
$\quad$ Typhoid fever & $3(10)$ \\
Hepatitis B & $4(13)$ \\
Pneumonia & $2(6)$ \\
Urinary tract infections & $5(16)$ \\
Colic abdomen & \\
Others & $21(71)$ \\
Therapy of antibiotics, $\mathbf{n}(\%)$ & $5(16)$ \\
Ceftriaxone & $3(10)$ \\
Cefotaxime & $1(3)$ \\
Ciprofloxacin & $3-21( \pm 7.65)$ \\
Meropenem & \\
Length of Stay (LOS), mean \pm SD &
\end{tabular}


The diagnosis of each patient included in this study varied greatly. The data were as follows: 2 or $7 \%$ suffered from chronic kidney disease, 5 patients or $16 \%$ suffered from diabetes mellitus, 5 patients or $16 \%$ diagnosed with fever observation, 3 patients or $10 \%$ suffered from typhoid fever, 3 patients or $10 \%$ suffered from hepatitis B, 4 patients or $13 \%$ suffered from pneumonia, 2 or $6 \%$ suffered from urinary tract infections, 2 or $6 \%$ suffered from abdominal colic and 4 or $16 \%$ suffered from other diseases namely SLE, Ca cecum, pulmonary TB HELLP syndrome and hypertension (Figure 2).

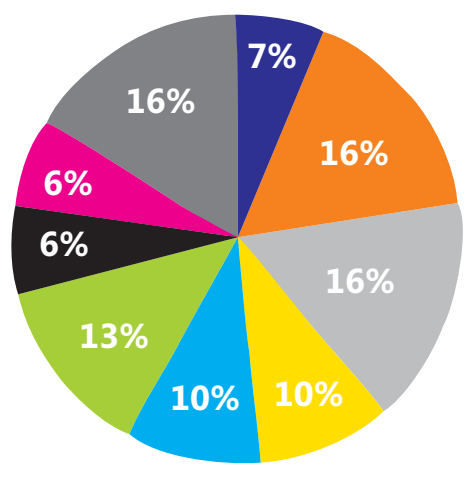
Chronic Kidney Disease
Diabetes Mellitus
Observation febrile
Typhoid fever
Hepatitis B
Pneumonia

Figure 2. Percentage of patient diagnosis

Based on the diagnosis, most diarrhea patients were found in those with a diagnosis of DM and febrile, which was as much as $16 \%$ and other diseases which also $16 \%$. This finding was probably due to the fact that in DM patients and fever might have an infection process which was then aggravated by irrational antibiotics.

Antibiotic therapy given to patients was also divided into several types: 21 or $71 \%$ treated with Ceftriaxone, 5 or $16 \%$ received Cefotaxime therapy, 3 or $10 \%$ received Ciprofloxacin therapy and 1 patient or $3 \%$ received Meropenem therapy. All drugs were given by intravenous injection (Figure 3).

Comparison of the characteristics of cases with C.difficile infection and non-cases of C.difficile infection in 2015 showed that antibiotics used in patients with C.difficile positivity included Penicillin, Cephalosporin, Macrolide, and Metronidazole. Data on antibiotic use in patients in this study also showed more or less the same results. The mostly used antibiotics in patients in this study were the $3^{\text {rd }}$ generation Cephalosporin antibiotics, Ceftriaxone.
All samples that were examined for culture gave 27 samples, which showed no pathogenic bacteria growth and three samples with positive pathogenic E.coli (ESBL) culture (Figure 4). The literature states that diarrheal-causing bacteria included Salmonella, Shigella, pathogenic E.coli, Campylobacter, Vibrio cholera, and Yersinia, but in fecal culture the conventional method carried out in this study could only detect Salmonella, Shigella, E.coli pathogens, Staphylococcus aureus, and Vibrio cholera.

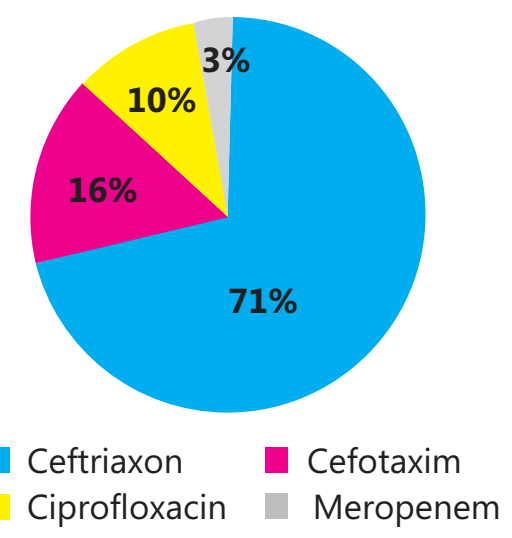

Figure 3. Percentage therapy of antibiotics

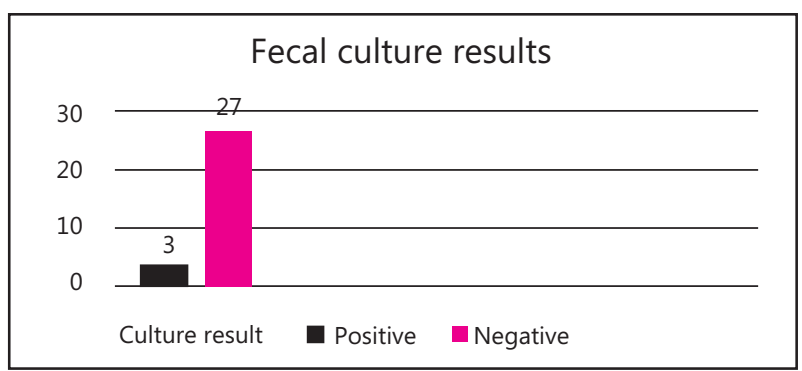

Figure 4. Fecal culture results

The results of positive pathogenic E.coli (ESBL) cultures from the three samples showed varying resistance, as shown in Table 2.

The sample collection period was ten months starting from August 2017 to May 2018. The results comprised 30 samples, and all of the samples had been examined for toxins and GDH enzymes in the previous studies using ICT and showed negative results. The sample with a negative result was then followed by an examination of fecal culture.

Patient demographic data in this study showed that of 30 adult patients taken from the Inpatient Ward and ICU of the Dr. Soetomo Hospital Surabaya, consisting of 20 female patients and 10 male patients. Based on the diagnosis, the most was diagnosed with diabetes mellitus, febrile observation, and other diseases as much as $16 \%$. The 
Table 2.The resistance of antibiotic sample with positive ESBL

\begin{tabular}{lccc}
\hline Antibiotics & Samples $\mathbf{1}$ & Samples & Samples 3 \\
\hline Ampicillin-Sulbactam & $\mathrm{S}$ & $\mathrm{S}$ & $\mathrm{S}$ \\
Amoxycillin-Clavulanic acid & $\mathrm{S}$ & $\mathrm{S}$ & $\mathrm{S}$ \\
Cephazolin & $\mathrm{R}$ & $\mathrm{R}$ & $\mathrm{R}$ \\
Cefotaxime & $\mathrm{R}$ & $\mathrm{R}$ & $\mathrm{R}$ \\
Ceftriaxone & $\mathrm{R}$ & $\mathrm{R}$ & $\mathrm{R}$ \\
Ceftazidime & $\mathrm{R}$ & $\mathrm{R}$ & $\mathrm{R}$ \\
Cefixime & $\mathrm{R}$ & $\mathrm{R}$ & $\mathrm{R}$ \\
Trimethoprim-Sulfamethoxazole & $\mathrm{R}$ & $\mathrm{R}$ & $\mathrm{R}$ \\
Amikacin & $\mathrm{S}$ & $\mathrm{R}$ & $\mathrm{S}$ \\
Gentamycin & $\mathrm{S}$ & $\mathrm{R}$ & $\mathrm{S}$ \\
Tetracyclin & $\mathrm{R}$ & $\mathrm{R}$ & $\mathrm{R}$ \\
Chloramphenicol & $\mathrm{R}$ & $\mathrm{R}$ & $\mathrm{R}$ \\
Ciprofloxacin & $\mathrm{R}$ & $\mathrm{S}$ & $\mathrm{R}$ \\
Levofloxacin & $\mathrm{R}$ & $\mathrm{S}$ & $\mathrm{R}$ \\
Meropenem & $\mathrm{S}$ & $\mathrm{S}$ & $\mathrm{S}$ \\
Piperacillin-Tazobactam & $\mathrm{S}$ & $\mathrm{S}$ & $\mathrm{S}$ \\
\hline
\end{tabular}

type of antibiotics obtained also varied, but the most common type was Ceftriaxone, which was $71 \%$, followed by Cefotaxime, which both were generation III Cephalosporins. The high usage of antibiotics and not as indicated was a factor that triggered resistance, which in turn could cause a decrease in the immune system.

Some published research evidence showed that the most common cause of acute diarrhea in various parts of the world, including Indonesia, was a rotavirus. The prevalence of bacterial, parasitic, and viral pathogens in 3875 patients with diarrhea in the community and hospitals studied from March 1997 to August 1999 in Jakarta were distinguished using routine bacteriology and molecular testing techniques. Pathogenic bacteria isolated included Vibrio cholera 01, Shigella flexneri, Salmonella spp., and Campylobacter jejuni. Pathogenic bacterias were isolated by $14 \%$ with diarrhea. Enterotoxigenic E.coli was detected in $18 \%$ of rectal swabs. The smallest percentage of E.coli enterohemorrhagic was only $1 \%$, Clostridium difficile $1.3 \%$, and parasite infection $11 \%$, rotavirus $37.5 \%$

The results of fecal culture from the 30 samples examined showed 3 samples with positive E.coli pathogens (ESBL/Extended-Spectrum Beta Lactamase) and 27 other samples that did not develop pathogenic bacteria. These results indicated that in 30 patients with diarrhea who received antibiotics at least $2 \times 24$ hours, the cause of the diarrhea was non-bacterial infections such as viral infections. Patients with long-term antibiotic use could cause antibiotic resistance so that sensitive bacteria became resistant.
A study conducted by Sangeetha et al. in India stated that $69 \%$ of Shigella bacteria in children with dysentery were resistant to Ciprofloxacin and Ceftriaxone. Rajeshwari et al. also conducted the same study in New Delhi with the result of Shigella bacteria resistant to Nalidixic Acid (95.7\%), Norfloxacin (87\%), and Amoxicillin (56.5\%). Tjaniadi et al. also conducted a study of the bacteria that caused diarrhea in Indonesia. The result was Shigella sp. and V.cholera O1, resistant to Ampicillin, Cotrimoxazole, Chloramphenicol, and Tetracycline; Campylobacter jejuni and V.cholera non-O1 were resistant to Ciprofloxacin, Norfloxacin, Ceftriaxone. ${ }^{6}$

The culture results from the three samples with the ESBL results showed that almost all antibiotics were resistant, except beta-lactamase inhibitors, Aminoglycosides, Carbapenem, and Piperacillin-Tazobactam, which still showed sensitive results in samples 1 and 3 . The second sample showed more resistance results than sample 1 and 2, which still showed sensitive results only in betalactamase inhibitors (Ampicillin-Sulbactam, Amoxicillin-Clavulanic Acid), Ciprofloxacin, Levofloxacin, Meropenem, and Piperacillin-Tazobactam.

Negative culture results provided an overview of other possible causes of diarrhea experienced, including those caused by viral, fungal, and parasitic infections. The certainty of the cause of diarrhea that occurred still requires further examination.

\section{CONCLUSIONS AND SUGGESTIONS}

The results of the research that had been carried out on 30 samples as a whole aimed to see the 
picture of culture results in diarrhea patients who received antibiotic therapy for more than two days other than those caused by C.difficile infection. The causes of diarrhea were very varied, indicated by the results of culture, which only gave positive results in 3 samples from 30 samples examined. The three samples that showed the results of $E$.coli pathogenic bacteria (ESBL) were associated with the presence of drug resistance. Most diarrhea occurring in patients in this study was caused by non-bacterial infections such as viruses, fungi or parasites. Determining the exact cause of diarrhea that occurred still requires further examination. The final conclusion was that diarrhea patients accompanied by antibiotics that were not due to C.difficile infection were due to non-bacterial infections such as viral infections and possibly other bacteria that could not be detected by this conventional method culture.

Limitations in the collection of samples that were still small and the culture method used can be a reference for other researchers to continue the study using a more significant number of samples and with more sophisticated examination methods to get better results.

\section{REFERENCES}

1. Ayu Ariani Wijaya. Diare pada pasien rawat inap di Rumah Sakit Umum Daerah Kabupaten Karanganyar Tahun 2009. 2009; 1.

2. Badan Penelitian dan Pengembangan Kesehatan. Riset Kesehatan Dasar (RISKESDAS) 2013. Lap Nas 2013. 2013; 114.

3. Depkes RI. Buletin diare. Jakarta, Departemen Kesehatan Republik Indonesia. 2016; 02: 26-30.

4. Jurnalis YD, Sayoeti Y, Ilmu B, Anak K. Pola resistensi kuman penyebab diare terhadap antibiotika. Maj Kedokt, 2008; 33(1):41-6.

5. Trisnowati $K E$, Irawati $S$, Setiawan E. Kajian penggunaan antibiotika pada pasien diare akut di bangsal rawat inap anak. Jurnal Manajemen dan Pelayanan Farmasi, 2017; 7(1): 16-24.

6. Elseviers MM, Van Camp Y, Nayaert S, Duré K, Annemans L, Tanghe $A$, et al. Prevalence and management of antibiotic-associated diarrhea in general hospitals. BMC Infect Dis, 2015; 17(15): 129. 